\title{
The challenges and opportunities of visually impaired students in inclusive education: The case of Bedlu
}

\author{
Mulat Alebachew Belay ${ }^{1}$ and Sileshi Goshu Yihun² \\ ${ }^{1}$ Bahir Dar University, Health Psychology, Ethiopia (ORCID: 0000-0003-3468-0596) \\ ${ }^{2}$ Bahir Dar University, Educational Policy and Planning, Ethiopia (ORCID: 0000-0002-9353-2916)
}

\begin{abstract}
Despite many efforts invested in for the successful implementation of inclusive Education in public primary and secondary schools in Ethiopia, there are still numerous challenges facing this area. This paper describes the challenges and opportunities in an inclusive education of a visually impaired student, Bedlu. In undertaking the study, a case study design was employed. In order to examine the thoughts of Bedlu, he was interviewed about his experiences at his school and in his class. In addition, his school and classroom setting was observed. Content analysis was done on the transcriptions of the interview data and the field notes. The findings show that even though there are some opportunities that support inclusive education, these opportunities do not guarantee their implementation effectively. The interview results indicated that inadequate budget, lack of necessary materials, absence of qualified professionals, shortage of professional growth, and development trainings were some of the major factors that hinder the full implementation of inclusive education. It was also concluded that the challenges outweigh the opportunity on the full implementation of inclusive education. As a recommendation, strong collaboration among stakeholders, non-governmental organizations along with the concerned bodies, training offered for professional teachers in special needs education, and appropriate budget allocation in order to realize the effective implementation of inclusive education were suggested.
\end{abstract}

Keywords: Inclusive education; Primary education; Visual impairment; Opportunuties; Challenges

Article History: Submitted 16 January 2020; Revised 1 April 2020; Published online 30 May 2020

\section{Introduction}

Education is a basic right in which every child must have the opportunity to achieve and maintain an acceptable level of learning. Education is the right of every child, which must be respected, and no child should be denied for it and the opportunity to complete tehir education (UNICEF, 2000). It is, therefore; educators have social responsibility to make the provision of education to all people based on their needs and abilities (Ürey \& Güler, 2018; Zegeye, 2019).

Among the different approaches to education, inclusive education is allowing all children to learn within school systems. According to this approach, not only normal students but also students with special needs are provided with specialized education in age-appropriate regular classes according to their special educational needs (Forman, 2002). In other words, inclusive education is all about welcoming all children to regular schools without any discrimination. It

Address of Corresponding Author

Mulat Alebachew Belay, Bahir Dar University, Health Pyychology \& Special Needs Education and Inclusive Education, Ethiopia.

$\triangle$ fekedebelay2@gmail.com

How to cite: Belay, M. A. \& Yihun, S. G. (2020). The challenges and opportunities of visually impaired students in inclusive education: The case of Bedlu. Journal of Pedagogical Research, 4(2), 112-124. 
should not set apart children who have different talents, abilities or needs, but process towards addressing the diversified needs and interests of all learners. Inclusive education is more than just placing a child with special educational needs in regular schools. Besides accommodating children in the regular or general school, it goes beyond that. It is also a way of thinking to offer special support within regular classrooms for all children irrespective of their diversified educational needs. The approach also focuses on children's needs and teachers training to facilitate an inclusive classroom which better meet the needs of all children (Tomlinson, 1996). Inclusion is about the changes in schools to improve the educational system for all learners. It includes changes in the curriculum, teaching methods and relationship in classrooms. This system ensures that every student participates fully in all aspects of life, physically, academically, socially and emotionally (Powers, 2002).

The provisions of inclusive education services get more attention by different international conventions and conferences. According to the Education for All Convention of UNICEF (2000), it was expected that impaired children would meaningfully gain access to the necessary inclusive education services.

Ethiopia has also accepted the UN's various international conventions and policy instruments even though the participation rate of children with disabilities was insignificant, and did not meet the diversified needs of children. For instance, according to United States Agency for International Development [USAID] (2011) report in Addis Ababa limited access to education, discrimination and stigma are attached to disabilities across different schools. Students with disabilities are not often encouraged to succeed. In addition, these remain insufficient based on the level of need and were inaccessible to the majority of Ethiopians with disabilities.

Similarly, other studies noted that in Ethiopia, out of the total population, very few are beneficiaries of government and non-government services. Only a few number of the school age children with disabilities has access to education. For instance, Education Sector Development Program [ESDP] (2010) reported that less than 3\% of them have access to primary education. In the same vein, Lewis (2009) showed that out of 691,765 disabled children in Ethiopia, only about 2,300 are enrolled in school 1, with a high risk of dropping out (MoE, 2012). In addition, a survey conducted in a cluster of schools with mainstreaming of disabled students in Ethiopia, $93.5 \%$ of the disabled students reported difficulty with receiving support from their parents, teachers and peers (Dagnew, 2013).

Generally, there is still a gap in providing access to all children and actualizing inclusive education. Access to educational opportunities, equity, and quality issues are still challenges in the provision of inclusive education for all children with special needs. The main barriers here are the lack of knowledge about diversity, inflexibility of the curriculum, insufficient preparation of teachers and education leaders, rigid and poor teaching methods, inconvenient learning environment, the lack of need identification processes, and inadequate assessment procedure (UNESCO, 2008). As a result, schools and teachers find it difficult to accommodate students with special needs and compel them to adapt to the school, instead of adapting schools to the needs of the students. As a result, the quality of education received by CWDs has remained to be ineffective (MoE, 2012).

Generally, the concept and practical activities of inclusive education need to be applicable in schools in Ethiopia because the country is not free from the practice of educational exclusion, particularly for people with different impairments. Hence, the researchers are highly inspired to investigate the challenges and opportunities of inclusive education in the selected school.

\subsection{Theoretical Framework}

Inclusive education is a multidimensional and complex system. The way to realizing its implementation is not easy, because different challenges will arise. However, its effective implementation requires the commitment and collaboration of different stakeholders. 
Though the importance of inclusive education for students with different impairments is incontestable due to the different factors its implementation remains ineffective. Even though there are ample ways in which learners with disabilities can be supported in a regular class, research shows that many learners with disabilities in mainstream schools are not always receiving the special educational services that they need to gain full access to the curriculum. For instance, school-based factors such as unavailability of instructional materials, the lack of learner-centered curriculum and inadequate teaching strategies in Kenyan schools are the major barriers related to the system. Most of the physical facilities in the schools were highly unsuitable for students with disabilities. Toilets, playgrounds, classrooms, and building designs are not adapted to suit the students. The play fields were littered with stones, grass, and pieces of wood exposing the learners to great dangers (Eunice, Nyangia, \& Orodho, 2015).

Insufficient learning resources such as textbooks and learning materials that support the needs of particular groups of learners such as Braille and easy reading materials are major barriers for visually impaired students in different countries of the World (UNESCO, 2009). In addition to poor access and shortage of resources, the implementation of inclusive education in some countries of the world is poor. UNESCO (2009) also noted that lack of policies and the issue of inadequate funding to a great extent also hinder the implementation of inclusive education in schools. Rigid regulations prevent resources from being attributed effectively where they are needed. Methods used are inflexible and only allow for one teaching style (UNESCO, 2009). Studies also showed that due to several factors inclusive education in Ethiopia is not fully implemented. Supporting this, Mitiku, Alemu, and Mengsitu (2014) suggested that the lack of educational materials written in Braille and other supportive materials in the library are major challenges to the implementation of effective inclusive education in Chilga and Tikil Dingay primary schools of Gondar city, Ethiopia.

In his study, Abebe (2014) noted that there is a critical shortage of learning aids for Students with Disabilities and even more teachers with disabilities work with little or no supportive materials in Yeka sub city, Addis Ababa. He further added that special needs education in Ethiopia has long suffered insufficient recognition and little understanding among government bodies at various levels, schools and the society at large. Besides, absence of formal training for school communities to raise their awareness on disabilities and lack of trained experts in inclusive education to help SWDs has made school life more difficult for SWDs. There is no responsible body at school to work on the identification of SWDs and to treat them accordingly.

In addition to poor access, the implementation of inclusive education in some countries of the world is poor. For instance, inclusive education in Uganda has not been accomplished due to different school related factors, including inappropriate curriculum, poor teaching style, lack of instructional materials, shortage of professionals in Special Needs Education, unfriendly environment and discrimination (Najjingo, 2009).

Other findings also showed that due to several factors inclusive education in Ethiopia is not fully implemented. Supporting this, Etenesh (2000) suggests that the lack of relevant facilities and materials is a major challenge to the implementation of effective inclusive education in Ethiopia. Similarly, Demisew (2014) indicates that the implementation of inclusive education in Ethiopia is affected by different factors such as lack of awareness about disability, scarcity of resources, inappropriate curriculum, shortage of trained and skilled teachers, poor teachers" competence, inadequate special needs education training provision at colleges and Universities, lack of budget and planning commitment. Similarly, inclusive education in Chilga and Tikil Dingay primary schools of Gondar city has not been accomplished due to different factors, including the lack of attention from the education office, reluctance of teachers to give any additional time to teach students with different impairments and inappropriate school compound (Mitiku, Alemu, \& Mengsitu, 2014).

Even if many studies conducted on the issue, there had not been any local research carried out on the implementation of inclusive education in Atse Sertse Dingil School, Bahir Dar city. In 
addition, since the target school in the area is on the way to exercise inclusive education, the researchers believe that there is a need to carry out a comprehensive study in order to identify the opportunities and challenges of visually impaired students in inclusive education and come up with possible solutions. Therefore, the purpose of the study was to find out the challenges and opportunities of visually impaired students from the perspective of a student, Budle, in inclusive education.

\subsection{The Aim}

This paper aims to investigate the challenges and opportinities of students with visual impirment in an inclusive education. More spesfically the study will be able to:

$>$ Assess the challenges of visual imparirment studensts in an inclusive classroom,

$>$ Identify the oppourtinities of students with visual impirment in an inclusive classroom.

\section{Method}

\subsection{Research Design}

In this study, a case study design was employed where a phenomenon related to challenges and opportunities from the perspective of a visually impaired student. Case studies are important to get detailed information related to contemporary phenomenon within real life situations (Yin, 2003). Even though there are different types of case study, in this study, a descriptive case study was employed. This type of case study is used to describe an intervention or phenomenon and the real-life context in which it occurred (Yin, 2003).

\subsection{Participant}

In this study, purposive sampling technique was employed to include one student with visual impairment whom the researchers observed his ups and downs in his social as well as educational life. Bedlu is a grade eight, 20 years old student, and he has been living with his 50 years old mother. Bedlu's mother earns her life by bagging money or other things around the church, and Bedlu and his mother live in a small house. Bedlu travels long distance on foot to school. He always wears his school uniform and he earns his life by collecting money from the street using digital glass weighing device by measuring people's weight. In addition, he has singing tallent which atracts the researchers' attention to conduct a case study on his academic challenges and opportunities. Bedlu lost his vision when he was 6 years old due to unknown cause and he is the only child for his parents. His father died when Bedlu was around 10 years old. As a result, the family's income got seriously affected following Bedlu's father's death because his father was the only person to provide the family income by trading sheep and goat at different market places. Both Bedlu's father and mother cannot read and write.

\subsection{Instruments and Data Collection}

As data collection tools, semi structured interview and observations were employed. The semi structured interview was conducted to gather information about the opportunities, challenges and possible remedies related to inclusive education. The interview questions, which were developed by researchers considering the related literature and expert opinions as in Appendix 1 . During the interview, to capture the response of the participant fully and to reduce the problem of note taking, audiotape recording was used based on the permission of participant.

Observations were also conducted for three days (40 minutes each) to gather sufficient ideas about teaching and learning processes in the classroom where the inclusive education is adopted. An observation checklist (see Appendix 2) was employed to find out the type of infrastructural and instructional facilities available in the school. Specifically, the learning materials (i.e., Braille texts, references, maps, etc.), the building's suitability, and the other physical environments such as the classroom settings, the office's layouts, the teachers' treatment, and others were observed. 


\subsection{Data Analysis}

In this study, the data were obtained using transcripts from semi-structured interviews and field notes from observations. Initially, the researchers conducted observation, before and after the interviews, for a period of three to four days. The observation notes were taken immediately after every observed activity was done. The field notes from the observation schedule were presented in report form. The data were grouped in themes such as challenges regarding the availability of facilities, infrastructures and the classroom situations. A summary of implications was given at the end of every category and theme that was taken from the field notes. The collected data through observation were analyzed using interpretative and reflective analysis that relied on the researchers own insight.

Second, the data obtained through semi structured interviews were presented and analyzed as follow: First of all, two independent researchers listened to the interviews from the audio recorder and transcribed them one by one. The transcribed data were re-read several times. The important issues from the responses per question were presented in a report form and in some cases, direct quotes were recorded. Then the collected data were organized in similar themes, including the availability of materials, budget, policy, school curriculum, teaching methodology. On the other hand, the data focusing on the issues related to support, opportunities and strategies in the process of inclusive education were collected and categorized based on their similar characteristics. Finally, content analysis was conducted. Inter-rater reliability value was found to be higher than .75 which indicates that the reliability of the analysis is within the acceptable range.

\subsection{Ethical Considerations}

This research study was conducted in line with research ethical issues. Permission was requested and sought from the school management and the participant before observation and an interview was conducted. The research participant was made aware of the purpose of the study to ensure his willingness and full participation. Detailed information was obtained from the participants on how the study was conducted and what was done with its result.

Respondent was also informed that there was no harm or coercion either before, to force participant to be involved, or during the study to get participant to disclose information. It was made clear that the participant participates in the study was purely voluntary. Furthermore, the participant was assured of the confidentiality of his identities before his participation in the study. The researchers informed the participant that real names and addresses must not be used in final report. Moreover, to make this study ethically sound, the researchers employed the guidelines formulated by Bogdan and Biklen (1998). Participants are informed consent and protection of participant from any form of psychological harm or danger.

\section{Results}

\subsection{The Benefits of Inclusive Education}

When Bedlu was asked about his feelings toward the importance of inclusive education, he expressed positively. For example, he responded that being in the same school and class with sighted learners made him feel welcomed and accepted in the school community. He stated that it helped him establish friendships and increases his social interactions and relationships with students with student without visual impairments. He further elaborates:

"I am very happy due to the support that I do receive from my classmates. They guide me to class, toilet and sometimes even when I go back home. I do not know what the situation could have been like if I were going to a school with together students without visually impairment only".

He added that his peers encourage him in different situations. Sometimes the sighted friends helped him to get his way when he is lost. He elaborates by saying: "Sometimes, I fail to do exercises given by the teachers as I have to wait for my few sighted friends to read their text books. Not only this but 
they tried to read their short note during exam time; they prepare and ask me some questions to evaluate my performance".

\subsection{Challenges of Inclusive Education}

\subsubsection{The skills, knowledge and methodology of teachers}

The questions in this key area aimed at establishing the extent to which teachers adapt the teaching methodologies and examinations to suit the needs of students with visual impairments. It is known that teacher's training is equally important in the teaching and learning process at all levels. Concerning this, Bedlu replied that most of his teachers did not have adequate skill and knowledge to treat the students with visual impairments. Similarly, the researchers observed that a classroom teacher did not have the appropriate skill and knowledge to address the diversified needs of students with visual impairment. According to the data gathered from both sources, the teachers have insufficiencies motivating and inspiring these groups as well as understanding the problems of those students during the teaching learning process. This includes promoting learning and supplementing activities, using a variety of teaching approaches, and adapting instruction to include all students. The classroom teacher is in charge of each student's overall academic program.

It is difficult to use a single method for teaching because students learn differently; single method does not satisfy the needs of all students. Concerning this, Bedlu agreed that the teachers' methodology is not comfortable for him. There is no special classroom support provided to him.

Similarly, the observation result indicated that students with visual impairments and students without visual impairments learn the same content using the same methodology. In addition, the researchers observed that the classroom teacher did not prepare any content or task separately for students with visual impairments. This is a big problem in the classroom. The teacher did not know how to treat and teach students with visual impairments. For example, as a researcher observes, one teacher was using words such as "this is," "The table indicates", "look", "you can see from the text on page", "as you see from the board" inside the classroom while he was teaching. Those words that the teacher used indicated that the teacher did not know how to teach visually impaired students.

\subsubsection{Support}

Bedlu, said that the majority of his teachers did not support him. They never worked with him. He felt very much bored. Except Braille, slate, and stylus, there was no special support from the school. The majority of his teachers treated him like sighted students. He further added "Teachers won't give me full marks just because I don't have exercise books. But how could this be? I don't even know how to write with ink. I don't really know the specific reason."

Bedlu, further argues, "I have no parents in Bahir Dar city." But there are partial cases of acknowledgements commending groups support. For instance, Bedlu said:

Few of my teachers sometimes give me moral support and encouragement even through phone calls. Thanks all of them. Otherwise, no one else helps me. Because of this, I asked myself why teachers cannot even ask me, "What are his problems?" or "How can they support me".

Bedlu, replied that he paid 350 Ethiopian Birr from the government monthly. He told the researcher that it is not even enough for his education. Therefore, Bedlu said, "I need support from different groups like money for food, house rent, and cloth and for buying necessary materials for his education" when possible.

\subsubsection{Teachers methodology}

Most teachers lacked training in special education and felt it contributed greatly to dissatisfaction of students especially those with visual impairment. Concerning this, Bedlu reported that "I think my teachers lacked training on how to teach students with visual impairments. Some of them try to teach us orally, but most of them do not care about us". Bedlu added that teachers allowed him 
to sit at the place of his personal choice. However, they did not show him tactile teaching aids. They mainly pay attention to sighted students. Bedlu said that majority of his teachers were not well trained and could not address the diversified needs of the leaners. He mentioned some indicators; they could not read and write Braille. And also, they did not consider students with visual impairments when teacher gave mark for students without visual impairment students for the neatness of their exercise books. Rather, teachers' rated " 0 " mark value for blind students due to that their haven't exercise books. Moreover, Bedlu further added the following:

"I think my teachers did not take any training on inclusive education and on how to teach students with visual impairments' because they teach us the same way as they teach sighted students. Few of our teachers leave the class after writing on the blackboard without giving explanations".

\subsubsection{Subject difficulty}

In this regard, Bedlu stated that the most difficult subjects for him were chemistry, physics, and mathematics simply because the medium of instruction was in English, and also it was due to the fact that those subjects often require visual imitation. He also told the researcher that English was one of the most difficult subjects for him because it required reading different supportive materials and text books. The reasons could be: "First I do not have any support from my family and neighbors to help me in reading and learning this subject; because most of them are not educated and they cannot read. Second, I didn't watch television because I did not have it so I could not develop my speaking and listening skills."

\subsubsection{Classroom Situation and Exam}

Concerning the classroom situation Bedlu replied as follows:

"When I cannot do what sighted students do, I feel that I am hopeless. In addition, when sighted students write a note from the blackboard, I feel so bad. I always think that sighted students can do a lot of things like walking alone, running, being happy at whatever they do and feeling satisfied in everything because they have the capability to do it. However, most of the time I am dependent on my sense of hearing, and I can only do a few things that I can hear, feel and touch. This makes me unhappy and worried".

Bedlu added: "I always need someone to read for me before the midterm and the final exams. It's difficult for my friends to assist me during this critical time". He always becomes much stressed and worried during the exams time, because he do not know how to manage his studies".

In inclusive class, special consideration must be given to the visually impaired students in the classroom aspect in general and on the time of examination in order to be successful in their academic performance. Concerning this, the interview and observation result indicated that similar examination is set for all types of learners that are, for both visually impaired and without visually impaired students who are attending in the same grade level.

One teacher respondent also claimed that while the sighted students take examinations in the classroom, students with visual impairment take examinations on the corridors. As a result, it is highly likely to be disturbed by noises. They take examinations on the corridors of the classrooms where sighted students are taking the examinations. This is also inconvenient as people create noises while they walk in the corridors. The school never arranged exam rooms and additional time to them. Supporting this, the school principal further argued by saying:

"Letting students with visual impairment take examinations on corridors and exposing them to noises is a reality. Students with Visual impairment are made to take the examinations by the help of their readers in the corridors around the room. They cannot be examined together with the sighted students in a room because when the readers read the examinations to them, the sighted ones will be disturbed." 


\subsubsection{Social Challenges}

Bedlu said, "I am suffering from lots of social challenges." He also reported that students with visual impairments support each other. Some sighted students, however, do not always support him. Therefore, he reported, "I feel sad and worried that why they are not voluntarily interested to support me." In addition, the researcher observed that interactions between students with visual impairment and students without visual impairment were not promising. They had good relationship with few students without visual impairment. Instead, students with visual impairment usually stick together. The researcher observed that students with visually impairment, they keep themselves together, like during break time they gathered and stayed together. They talked and laughed; they have good relationship with each other's.

\subsubsection{Psychological Challenges}

Bedlu said that being visually impaired makes him to feel bad. He regretted by saying that why God create him different from other people. He added, "If I were sighted I could work just like my sighted friends". Bedlu stated:

"When I was in lower grades I felt bad, because I was considered myself as useless. But now, I understood that being without sight is nothing and now I became hopeful. If I learn, I can lead my life just like "normal people". The main purpose of education is to lead better ways of life, so if I am an educated person, no matter what my problem is, I can live in a good situation. However, still, I feel bad especially when my teachers tell me to beg my sighted classmates to read what my teacher wrote on the blackboard."

Bedlu also expressed his hope by saying:

"After I knew many successful persons with visual impairments, I thought that I am a human being like any other people. However, still, I was thinking that how could I lead my life. Again when I know that students with visual impairment can learn, I started to adjust my mentality."

He says that when his classmates help him by reading from the blackboard and books, he worries that students may be tired. As a result, he gets emotional. To solve this psychological problem and be certain, he reads the book written in Braille at the school and outside the school with other visually impaired students.

\subsubsection{Resources and Funding}

The issue of inadequate funding to schools to a great extent hinders implementation of inclusive education. Concerning this, Bedlu indicated that lack of or inadequate teaching and learning resources contributed to hindering the school from practicing effective inclusive education.

Bedlu narrated that unsuitable infrastructure, inadequate learning resources; shortage of trained teachers in inclusive education could all be attributed to insufficient funding by the government and the school.

A library service is one of the other school facilities that contribute to effective teaching and learning activities in the school. It is useful to teachers and students by providing reference materials, which enhance further understanding of different subjects. Concerning the availability of special materials and equipment and library services, the researcher observed that there were no necessary special educational materials and equipment such as audio recorder and handouts, modules and other reference materials written in Braille. Bedlu supported the lack of learning resources. He said that libraries were not equipped with the necessary resources for students with visual impairments making it difficult for them to enjoy the library services especially when doing their assignments and revisions for their exams.

\subsubsection{The Environment}

Concerning the conduciveness of the physical environment for the teaching learning process, the researcher observed that the school compound was not totally suitable enough for students with 
visual impairment. They could not move from place to place without any supporter. The narrowness of the school compound might affect the mobility of the students because it was crowded by students during the break time, and as a result, they sometimes prefered to stay on the floor in the break time. This createed depression and feeling of inferiority on the side of the students with visual impairments.

In addition to the school environment, the out of school environment can be a big challenge for students with visual impairments. Concerning this, Bedlu said that when he went out alone at nighttime, he faced a problem because he walked and he bumped into stones, trees, and buildings. Bedlu also mentions that when he travels or walks long distances, he fears different obstacles like car accidents and losing the way he wants to arrive. So he feels uncomfortable. But walking over short distances is not as such a problem because he adapted to the place quite well. Moreover, the researchers observed a few obstacles on the school grounds that could possibly be barriers to learners with visual impairment. The school has a lot of big trees and this could hinder the students with visual impairment moving from one class to another without the support of others. Since the school is closer to the main road I would say the environment is not really comfortable. Moreover, students with visual impairment did not have proper toilet separately. This makes them worried.

\subsection{Possible Solution}

It is commonly agreed that teachers training in Special Needs Education is significant to address the diversified needs of students with visual impairments in inclusive class. Bedlu also replied that there must be a resource room equipped with the necessary materials to provide the service for students with special needs. Teacher training is important because it shapes teachers attitudes and equips teachers with adequate knowledge and skills in interacting with children with disabilities. Concerning this, Bedlu added that teachers should get adequate training to update their knowledge and know how to use alternative teaching procedures in order to address the diversified educational needs and teach in accordance with their potential. He also put forward the following idea as a strategy to implement inclusive education effectively. He stated:

"I think more qualified professional teachers in Special Needs Education are needed for the effective implementation of inclusive education. I feel it is good to train many teachers because they can create conducive learning environment for all learners in schools, they can treat learners with impairments and make them feel loved since these children always feel lonely."

He further elaborated:

"Frankly speaking, I suggest well organized training in the area of inclusive education is needed for teachers and students with impairments in different schools of our country. I feel like the government and other concerned bodies should provide more funds to train more special needs teachers so as to make inclusive education effective."

Working together as a group towards a common objective is important to make inclusive education effective. Concerning this, Bedlu replied that there must be cooperation, financial, material and moral support from the concerned bodies to be effective in his educational life. It is not the responsibility of schools alone to train teachers in special needs education in order to make inclusive education effective, but rather all learning institutions should take part.

At the end, the researcher asked him to say something about his future performance and things to be done. Accordingly, Bedlu narrated the following:

"We just need some more equipment and materials which make life easier for us, we have very little; our need is not fully addressed. We need financial and moral support, so if we get this, I promise that we will do better in our school work and we will have a bright future." 


\subsection{Opportunities}

Bedlu reported that the presence of few teachers who provide moral support for students with visual impairment could be considered as an opportunity to implement inclusive education effectively. He also added that students' network and support of his friends can be taken as opportunity to achieve his educational objectives. As to him, the availability of student text books which is written by the Education Bureau can be considered as opportunity. The monthly financial support by the government also considered as opportunity.

\section{Discussion}

The finding showed that in the selected school there is no periodic assessment to know the challenges of students with visual impairments. In contrary to this, Polloway and Patton (1997) emphasize periodic assessment is vital in inclusive education. According to Polloway and Patton (1997), since children need change from month to month and from year to year, regular periodic assessment must be conducted.

The findings also indicated that teachers did not try to slow their speed while presenting the lessons in order to help the students. Teachers did not give extra time for students with special needs to complete their activities. However, Heward and Orlansky (1992) claim that regardless of the degree of impairment, teaching procedure for students with special needs is implemented based on special time allotment for task completion.

In order to ensure that, inclusive education takes place there are many things to be considered. Concerning this, Msuya (2005) suggests that necessary facilities like teaching and learning materials, equipment and some environmental settings that are important for children with special needs should be considered in an inclusive context. Specifically, he mentioned facilities like Braille materials, audio and visual devices, various teaching aids, mobility equipment like white cane for the blind, special classroom designs and toilets are necessary for students with special needs. In contrast, the findings of this study indicated that there is a shortage of Braille, reference book written in Braille, audio recorder and other necessary materials in the library.

The finding revealed that the same examination is set for all types of learners who are attending in the same grade level. But this is not accepted by different research studies. For instance, Gearheart et al. (1992) suggested that testing procedures may have to be modified for the students who are visually impaired. Reading braille takes considerably longer time than reading standard print and it may be necessary either to extend the amount of time for completion of tests or reduce the number of test items, such students should not be penalized if they cannot finish tests because of the tools they are using. Students with visual impairment take longer time to read a text than students with normal vision Students with visual impairment complete their work very slowly due to the nature of their impairment (Mastropieri \& Scruggs, 2010). Therefore, extra time allowance is extremely important for them to process visual information, and complete their written assignments (Salisbury, 2008). Generally, it is acceptable to add half of the time for students with low vision, and twice as much for students with blindness (Spungin, 2002). Extra time will frequently be needed to complete assignments and exams (Kirk et al., 1993).

As a solution, the education sector development program (ESDP III as cited in UNESCO, 2008) recommended that awareness creation among school managers and teachers about the need to provide supports to all groups of learners, create identification of procedures, develop support systems, avail appropriate materials and equipment, including Braille and related instruments for children with visual impairments in schools are essential for successful inclusion of all citizens in schools. It is also supported by the findings of this study.

\section{Conclusion}

Based on the findings of the study, it is possible to draw the following conclusions. First, the school has little opportunities and these opportunities did not pave the way to implement inclusive education. And the school faced many challenges to implement inclusive education. Some of the 
challenges to implement inclusive education in this school are lack of educational materials, lack of skilled man power etc.

Furthermore, the school does not conduct scientific and periodic assessment to identify and know the degree of the needs of children with visual impairment. Although teachers tried to use different teaching strategies to involve students with special needs in all activities, they do not provide extra time to complete their activities, and the testing procedures are not modified and adapted for them. There is a shortage of special educational materials and equipment in the library and resource room such as handouts, modules and reference books written in Braille.

\section{Limitations}

As in every study, there are also some limitations in this current study. Since the researchers were interested in learning more about the challenges of Bedlu, it is difficult to generalize the finding to represent the challenges of other visually impaired students in his school. There was only one participant in this study. In addition, due to distractibility of Bedlu, the researchers were not allowed to use camera. Thus, the researchers felt that impotent information that shows his ways of living in the street were missed.

\section{References}

Abebe, D. (2014). Inclusive Education Practices of Primary Schools in Yeka Sub City (Unpublished Master"es Thesis). Addis Ababa University, Ethiopia.

Bogdan, R. C., \& Biklen, S. K. (1998). Qualitative research for education: An introduction to theory and methods (3rd ed.). Boston: Allyn and Bacon.

Dagnew, A. (2013). Factors affecting the implementation of inclusive education in primary schools of Bahir Dar town administration'. Education Research Journal, 3(3), 59- 67.

Demisw, A. (2014). Inclusive education practices of primary schools in Yeka Sub City. Unpublished doctoral dissertation, Addis Ababa University, Addis Ababa.

Education Sector Development Program [ESDP] IV (2010). Education Sector Development Program IV (2010/2011-2014/2015), $\quad$ Program Action Plan/PAP, Ministry of Education, Addis Ababa. Retrieved from http:// phe-ethiopia.org/pdf/ESDP\%20IV\%20Final\%20Working\%20Document.pdf on January 2020.

Etenesh, A. (2000, July). Inclusion of children with disabilities (CWD): Situational analysis of Ethiopia. Paper presented at $5^{\text {th }}$ International Special Education Congress, University of Manchester, UK.

Eunice, L. A., Nyangia, E. O., \& Orodho, J. A. (2015). Challenges facing implementation of inclusive education in public secondary schools in Rongo Sub- County, Migori County, Kenya. IOSR Journal of Humanities and Social Science (IOSR-JHSS), 20(4), 39-50.

Forman, P. (2002). Integration and Inclusion inAction. Baltimore: Paul H. Brook.

Gearheart, B. R., Weishahn, M. W., \& Gearheart, C. J. (1992). The exceptional student in the regular classroom. Ohio: Merrill Publishing Company.

Heward, W. L., \& Orlansky, M. D. (1992). Exceptional children: An introductory survey of special education. New York: Merrill.

Kirk, S.A, Gallagher, J. J., \& Anastasiow, N.J. (1993). Educating exceptional children (7th Ed). Boston: Houghton Mifflin Company.

Lewis, I. (2009) Education for disabled people in Ethiopia and Rwanda. Retrieved from http:// unesdoc.unesco.org on February 2019.

Mastropieri, M.A. \& Scruggs, T.E. (2010). The inclusive classroom: strategies for effective differentiated instruction. New Jersey: Upper Saddle River.

Mitiku, W., Alemu, Y., \& Mengsitu, S. (2014). Challenges and opportunities to implement inclusive education. Asian Journal of Humanity, Art and Literature, 1(2), 118-135.

Ministry of Education [MoE], (2012) Special Needs/Inclusive Education Strategy. Author: Addis Ababa, Ethipia.

Msuya, M. L. (2005). An assessment of primary education development plan (PEDP) implementation: A case of Mara region. Unpublished master's dissertation, University of Dar-es Salaam, Dar es Salaam.

Najjingo, H. (2009). Challenges of accessing all-inclusive education services by children with disabilities (Cwds): A case of Mijwala Sub-County Ssembabule District. Unpublished master's theis, Makerere University, Kampala. 
Polloway, E. A., \& Patton, J. R. (1997). Strategies for teaching learners with special needs (6th ed.).Columbus, $\mathrm{OH}$ : Merrill.

Powers, S. (2002). From concepts to practice in deaf education: A United Kingdom perspective on inclusion. Journal of deaf Studies and deaf Education, 7(3), 230-243.

Salisbury, R. (2008). Teaching pupils with visual impairment: a guide to making the school curriculum accessible. London: Routledge: Taylor \& Francis Group.

Spungin, S.J. (2002). When you have a visually impaired student in your classroom: A guide for teachers. New York: AFB Press.

Tomlinson, S. (1996).Educational sub normality: A study in decision-making. London: Routledge and Kegan Paul.

UNESCO (2008). Preparatory report for the 48th ICE on inclusive education. Retrieved form https://unesdoc.unesco.org/ark:/48223/pf0000182704 on June 2019.

UNESCO (2009). Policy guidelines on inclusion in education. Paris: UNESCO.

UNICEF (2000).Defining Quality in Education.A World Fit for Children. New York: A Publication of UNICEF Programme Division Education.

United States Agency for International Development [USAID] (2011). 2011 annual report American schools and hospitals abroad (ASHA). Retrived from https://www.usaid.gov/sites/default/files/documents/1866/2011\%20USAID-ASHAAnnual\%20Report.pdf on September 2019.

Ürey, M., Güler, M. (2018). A qualitative study on how students with visual impairments perceive environmental issues. Journal of Science Education for Students with Disabilities, 21(1), 15-28.

Yin, R. K. (2003). Case study research: Design and methods (3rd Ed.). Thousand Oaks, CA: Sage Publications, Inc.

Zegeye, T. G. (2019). An investigation on the status of resilience among blind adolescent students. Journal of Pedagogical Research, 3(1), 50-59.

\section{Appendix 1. Interview protocol}

Data collection tools,

Dear participant thank you for your willingness to participate in this study. Your genuine information is vital for this study. We assure that all your information must keep secret and your actual name will not be mention in the paper during data analysis. You have the right to withdraw from participating in the study.

Thank you!

\section{Semi structure interview guide question}

1. What do you think about the Benefits of Inclusive Education?

2. Could you please tell the Challenges of Inclusive Education regarding the following issues?

- Skills, Knowledge and Methodology of Teachers,

- $\quad$ support system of the school

- $\quad$ which subjects for you

- Classroom situation and exam

- Psychosocial related challenges

- Resources and Funding

- The Environment

3. What do you think about masseurs need to be taken to minimize the above challenges?

4. Could you please tell us about the opportunities? 
Appendix 2. Observation checklists

No. Points to be observed

Researchers Judgment

Poor Good Very good Excellent

\begin{tabular}{ll}
1 & Inclusive education classroom practice \\
\hline 2 & instructional facilities available in the school
\end{tabular}

(Braille texts, references and maps, )

3 School Accessibility such as the buildings suitability, and the other physical environments the classroom settings, the offices layouts, the teachers and treatment 